\title{
ASSESSMENT OF RIGHT VENTRICULAR FUNCTION IN ACUTE ST-ELEVATION MYOCARDIAL INFARCTION BY ECHOCARDIOGRAPHY
}

\author{
Karodi Murali Krishna ${ }^{1}$
}

${ }^{1}$ Assistant Professor, Department of Cardiology, Guntur Medical College, Guntur.

\begin{tabular}{l}
\hline ABSTRACT \\
BACKGROUND \\
Right Ventricular (RV) function has been shown to be a major determinant of clinical outcome and consequently should be \\
considered during clinical management and treatment. Thus, the need for diagnosis of RV dysfunction is evident.
\end{tabular}

\section{MATERIALS AND METHODS}

200 consecutive patients admitted with Acute ST-Elevation Myocardial Infarction to the ICCU of Osmania General Hospital, Hyderabad during the period of Jan. 2013 to Dec. 2013. All patients who presented with ST Elevation Myocardial Infarction for the first time within the 5 days of onset of symptoms, irrespective of age, gender and treatment status were included.

\section{RESULTS}

Incidence of RV dysfunction in study population by TAPSE<1.5 cm was 44 (22\%). 23 (29.1\%) patients with Inferior wall MI had RV dysfunction and 21 (17.3\%) patients with anterior wall MI had RV dysfunction. Out of 200 patients with acute myocardial infarction, 22\% (44/200) had RV dysfunction. Mean age of patients in RV dysfunction group was $57.4 \pm 11.3$ years and of patients in no-RV dysfunction (Normal RV function) group was $52.3 \pm 11.2$ years ( $\mathrm{p}=0.008) .15 .9 \%(7 / 44)$ patients in RV dysfunction group had past history of Coronary artery disease compared to $5.8 \%(9 / 156)$ in normal RV function group $(\mathrm{p}=0.02)$.

\section{CONCLUSION}

Nearly one fourth of patients with Acute ST-Elevation Myocardial Infarction had right ventricular dysfunction. LV dysfunction contributes significantly to RV dysfunction in acute myocardial infarction more so in anterior wall MI.

\section{KEYWORDS}

Right Ventricular Function, Acute ST-Elevation Myocardial Infarction, Echocardiography, TAPSE, RV FAC.

HOW TO CITE THIS ARTICLE: Krishna KM. Assessment of right ventricular function in Acute ST-Elevation Myocardial Infarction by echocardiography. J. Evolution Med. Dent. Sci. 2017;6(87):6001-6004, DOI: 10.14260/jemds/2017/1305

\begin{abstract}
BACKGROUND
Right Ventricular (RV) function may be impaired either by primary right-sided heart disease, or secondary to left-sided cardiomyopathy or valvular heart disease. In addition, it should be considered that RV dysfunction may affect left ventricular (LV) function, not only by limiting LV preload, but also by adverse systolic and diastolic interaction via the interventricular septum and the pericardium (ventricular interdependence). Moreover, RV function has been shown to be a major determinant of clinical outcome and consequently should be considered during clinical management and treatment. Thus, the need for diagnosis of RV dysfunction is evident.
\end{abstract}

\section{MATERIALS AND METHODS}

Study population: 200 consecutive patients admitted with Acute ST-Elevation Myocardial Infarction to the ICCU of Osmania General Hospital, Hyderabad during the period of Jan. 2013 to Dec. 2013.

'Financial or Other Competing Interest': None.

Submission 16-09-2017, Peer Review 17-10-2017,

Acceptance 24-10-2017, Published 30-10-2017.

Corresponding Author:

K. Murali Krishna,

D. No. 4-19-115/1,

Vikar Nagar, $4^{\text {th }}$ Line,

Guntur-522006, Andhra Pradesh, India.

E-mail: drmuralikrishnakarodi@gmail.com

DOI: $10.14260 /$ jemds $/ 2017 / 1305$

\section{Study Design}

Hospital-based descriptive study.

\section{Inclusion Criteria}

All patients who presented with ST Elevation Myocardial Infarction for the first time within the 5 days of onset of symptoms, irrespective of age, gender and treatment status.

\section{Exclusion Criteria}

Patients with past history of Q-wave myocardial Infarction, Chronic obstructive pulmonary disease, Pulmonary arterial hypertension, Chronic Rheumatic heart disease, Cardiomyopathies, Congenital heart diseases, Poor echo window for assessment of Right Ventricle and those unwilling for the study.

All patients were clinically evaluated. Detailed history noted from patients, attendants and from first clinical clerking from the documents available. Detailed general examination done. Vitals recorded. JVP evaluated, a thorough cardiovascular examination done. All the details were entered in a proforma.

ECGs recorded at admission with BPL Cardiart machine, a 12-lead single channel ECG, with additional leads of V3R, V4R in case of inferior wall MI, at $25 \mathrm{~mm} /$ second speed and at 10 $\mathrm{mm} / \mathrm{mV}$ standardisation.

All the patients were subjected to two-dimensional echocardiography, M-mode and Doppler echocardiography within one day of admission. Echocardiographic examinations were performed on Philips iE33 machine with a system equipped with Doppler tissue imaging. 
Assessment of Right Ventricular Function

Tricuspid Annular Plane Systolic Excursion (TAPSE) ${ }^{[1,2]}$

In real time, two-dimensional apical four chamber view Mmode cursor was placed through the junction of tricuspid valve plane and RV free wall in such a way that annulus moved along the M-mode cursor. The systolic displacement of tricuspid annulus towards the cardiac apex was recorded in M-mode. The total displacement was the vertical distance from the crest to trough of the leading edge obtained in $\mathrm{M}$ mode due to the movement of annulus. The distance was measured using the calliper inbuilt in echo machine. Units were expressed in centimetres. A cut-off value of $<1.5$ centimetres was taken for identification of patients with RV dysfunction.

\section{Right Ventricular Fractional Area Change (RV FAC) ${ }^{[3,4]}$}

RV function was assessed quantitatively using echocardiographic analysis as percentage of change in cavity area from end diastole to end systole in apical four chamber view. End diastole was considered as the frame at the onset of R-wave from simultaneously recorded electrocardiogram on echo machine; end systole was regarded as smallest right ventricular cavity size before tricuspid valve opening. Using apical four chamber view, endocardial border of right ventricular free wall and septum were traced from base to apex.

Right Ventricular Fractional Area Change was Calculated by the Formula Given Below-

\section{END DIASTOLIC AREA - END SYSTOLIC AREA x 100 END DIASTOLIC AREA}

Doppler Tissue Imaging for Assessment of Peak Systolic Velocity of Tricuspid Lateral Annulus.(Sa) ${ }^{[2,5]}$

In two dimensional apical four chamber view, in a tissue Doppler imaging mode, sample volume placed on tricuspid annulus at the place of attachment of anterior leaflet of tricuspid valve. Ultrasound beam was placed parallel to the direction of tricuspid annular motion. Peak systolic annular velocity recorded at speed of $75 \mathrm{~mm} / \mathrm{s}$ for subsequent analysis. The minimal gain was used to assure clear and welldefined pulse Doppler tissue imaging in left lateral decubitus position in end expiratory phase. Three consecutive cardiac cycles were measured for peak tissue velocity and mean was taken. For measuring peak tissue velocities calliper present in echo machine was used. Units expressed in centimetres per second $(\mathrm{cm} / \mathrm{s})$

\section{Statistical Methods}

Data was analysed using SPSS 16.0 statistical package. All categorical variables were expressed as numbers and percentages and the significant differences were analysed by Chi-square test. All continuous variables were expressed in mean \pm Standard deviation (SD) and the differences between the groups were analysed by Student t-test. The difference in the means in between multiple groups was analysed by analysis of variance (ANOVA). A value of $p<0.05$ was considered statistically significant.

\section{RESULTS}

200 consecutive patients with Acute ST-Elevation Myocardial Infarction were evaluated in this study. Among 200 patients, 157 (78.5\%) were male. Mean age was $53.35 \pm 11.48$ years.

\section{Presenting Complaints}

195 (97.5\%) patients presented with chest pain, 91 (45.5\%) had shortness of breath, 31 (15.5\%) had orthopnoea, $10(5 \%)$ had syncope, 57 (28.5\%) had palpitations, 57 (28.5\%) had restlessness during presentation.

\section{Location of MI}

$121(60.5 \%)$ had anterior wall myocardial infarction (AWMI), 79 (39.5\%) had inferior wall myocardial infarction (IWMI) out of which $56(28 \%)$ had inferior wall MI without RV MI and $23(11.5 \%)$ had inferior wall MI with RV MI.

$113(56.5 \%)$ were treated with thrombolytic therapy, $87(43.5 \%)$ did not receive thrombolytic therapy. $8(4 \%)$ patients died.

\section{Incidence of RV Dysfunction in Study Population}

$\mathrm{RV}$ dysfunction by TAPSE $<1.5 \mathrm{~cm}$

Total number of patients with RV dysfunction was 44 (22\%). 23 (29.1\%) patients with Inferior wall MI had RV dysfunction and 21 (17.3\%) patients with anterior wall MI had RV dysfunction.

\begin{tabular}{|c|c|c|}
\hline & $\begin{array}{c}\text { No. of } \\
\text { Patients }\end{array}$ & $\begin{array}{c}\text { No. of Patients with RV } \\
\text { Dysfunction }\end{array}$ \\
\hline All MIs & 200 & $44(22 \%)$ \\
\hline AWMI & 121 & $21(17.3 \%)$ \\
\hline IWMI & 79 & $23(29.1 \%)$ \\
\hline
\end{tabular}

Table 1. Incidence of RV Dysfunction in Study Population

Incidence of LV Dysfunction in the Study Population In the study population, $32.5 \%(65 / 200)$ had no LV dysfunction, while $37.5 \%$ (75/200) had mild LV dysfunction, $26 \%(52 / 200)$ had moderate LV dysfunction and $4 \%(8 / 200)$ had severe LV dysfunction.

\section{RV Function in Relation to LV Function}

LV dysfunction contributes significantly to RV dysfunction in acute myocardial infarction more so in anterior wall MI. As the severity of LV dysfunction increases RV function worsens which was statistically significant $(\mathrm{p}<0.05)$.

\begin{tabular}{|c|c|c|c|c|c|}
\hline & \multicolumn{4}{|c|}{ LV DYSFUNCTION } & \\
\hline & $\begin{array}{c}\text { No LV } \\
\text { Dys- } \\
\text { function } \\
\text { (n=65) }\end{array}$ & $\begin{array}{c}\text { Mild } \\
(\mathbf{n = 7 5 )}\end{array}$ & $\begin{array}{c}\text { Moderate } \\
(\mathbf{n = 5 2})\end{array}$ & $\begin{array}{c}\text { Severe } \\
(\mathbf{n = 8 )}\end{array}$ & $\begin{array}{c}\mathbf{P} \\
\text {-value* }\end{array}$ \\
\hline TAPSE (cm) & $1.88 \pm 0.3$ & $1.78 \pm 0.2$ & $1.66 \pm 0.3$ & $1.45 \pm 0.3$ & $<0.001$ \\
\hline Sa (cm/s) & $11.6 \pm 2.3$ & $11.6 \pm 1.7$ & $10.9 \pm 2.6$ & $8.7 \pm 1.8$ & 0.003 \\
\hline RVFAC (\%) & $44.9 \pm$ & $44.5 \pm$ & $40.8 \pm$ & $38.8 \pm$ & 0.025 \\
\hline $\begin{array}{c}\text { No. of pts. } \\
\text { With RV } \\
\text { dysfunction }\end{array}$ & $\begin{array}{c}12.2 \\
(15.4 \%)\end{array}$ & $\begin{array}{c}12.2 \\
(16 \%)\end{array}$ & $\begin{array}{c}17.9 \\
(32.7 \%)\end{array}$ & $\begin{array}{c}5 \\
(62.5 \%)\end{array}$ & $0.002^{* *}$ \\
\hline
\end{tabular}

Table 2. RV Functional Parameters with Respect to $L V$ Function

*ANOVA test applied, ** Chi square test applied. 


\section{RV Function in Relation to Thrombolytic Therapy}

The mean TAPSE was similar in both the groups of patients $(1.77 \pm 0.3 \mathrm{~cm})$. Mean tricuspid annular peak systolic velocity (Sa) was $11.4 \pm 2.3 \mathrm{~cm} / \mathrm{s}$ in patients who were given thrombolytic therapy compared to $11.2 \pm 2.2 \mathrm{~cm} / \mathrm{s}$ in whom thrombolytics were not given. Mean RV FAC in patients in whom thrombolytics were given was $42.7 \pm 11 \%$ compared to $43.5 \pm 12 \%$ in patients in whom thrombolytics were not given. These RV functional parameters in relation to thrombolytic therapy was statistically not significant $(\mathrm{p}>0.05)$.

\begin{tabular}{|c|c|c|c|}
\hline & \multicolumn{2}{|c|}{ Thrombolytic Therapy } & \\
\hline & $\begin{array}{c}\text { Given } \\
(\mathbf{n = 1 1 3})\end{array}$ & $\begin{array}{c}\text { Not given } \\
\text { (n=87) }\end{array}$ & p-value \\
\hline TAPSE (cm) & $1.77 \pm 0.3$ & $1.77 \pm 0.3$ & 0.993 \\
\hline Sa (cm/s) & $11.4 \pm 2.3$ & $11.2 \pm 2.2$ & 0.528 \\
\hline RV FAC (\%) & $42.7 \pm 11$ & $43.5 \pm 12$ & 0.653 \\
\hline $\begin{array}{c}\text { Patients with RV } \\
\text { dysfunction }\end{array}$ & $25(22.1 \%)$ & $19(21.8 \%)$ & 0.962 \\
\hline
\end{tabular}

Table 3. RV Functional Parameters and Patients with RV Dysfunction with Respect to Thrombolytic Therapy

Comparison of Demographic Features between Patients with Normal RV Function and RV Dysfunction

Out of 200 patients with acute myocardial infarction, 22\% $(44 / 200)$ had RV dysfunction.

Mean age of patients in RV dysfunction group was $57.4 \pm$ 11.3 years and of patients in no RV dysfunction (normal RV function) group was $52.3 \pm 11.2$ years ( $\mathrm{p}=0.008$ ). 15.9\% (7/44) patients in RV dysfunction group had past history of Coronary artery disease compared to $5.8 \%(9 / 156)$ in normal $\mathrm{RV}$ function group $(\mathrm{p}=0.02)$.

\begin{tabular}{|c|c|c|c|}
\hline & $\begin{array}{c}\text { Normal RV } \\
\text { Function } \\
(\mathbf{n = 1 5 6 )}\end{array}$ & $\begin{array}{c}\text { RV } \\
\text { Dysfunction } \\
\text { (n=44) }\end{array}$ & p-value** \\
\hline Age (years) & $52.3 \pm 11.2$ & $57.4 \pm 11.3$ & $0.008^{*}$ \\
\hline Male (\%) & $125(80.1 \%)$ & $32(72.7 \%)$ & 0.29 \\
\hline $\begin{array}{c}\text { Hypertension } \\
(\%)\end{array}$ & $53(34.0 \%)$ & $19(43.2 \%)$ & 0.26 \\
\hline Diabetes (\%) & $46(29.5 \%)$ & $10(22.7 \%)$ & 0.37 \\
\hline Smoking (\%) & $100(64.1 \%)$ & $28(63.6 \%)$ & 0.95 \\
\hline $\begin{array}{c}\text { Tobacco } \\
\text { chewing }\end{array}$ & $28(17.9 \%)$ & $8(18.2 \%)$ & 0.97 \\
\hline $\begin{array}{c}\text { Past H/0 } \\
\text { CAD (\%) }\end{array}$ & $9(5.8 \%)$ & $7(15.9 \%)$ & 0.02 \\
\hline
\end{tabular}

Table 4. Comparison of Demographic Features in Patients with Normal RV Function to those with RV Dysfunction

*Student $\mathrm{t}$ test applied, **for rest 6 variables, chi square test applied.

\section{DISCUSSION}

In the present study, RV dysfunction was present in $22 \%$ (44) of the patients, which was close to that of the study by Zornoff et al[3] in which $19 \%$ of patients had RV dysfunction in early AMI.

Patients who had RV dysfunction were significantly older compared to those who had normal RV function. This finding is concordant with the study by Gloria Tamborini et al.[6] which concluded TAPSE was negatively related with age, and also with the study of Zornoff et al..[3]

No significant difference noted with regards to gender distribution, frequency of hypertension, diabetes, smoking or other forms of tobacco usage in patients with or without RV dysfunction. These observations were similar to those of Zornoff et al[3] in their study of 416 patients with acute MI.

Significantly higher number of patients in RV dysfunction group had past history of coronary artery disease. This observation was consistent with that of the study by Zornoff et al.[3] in which previous coronary artery disease was significantly high in the patients with RV dysfunction.

All the echocardiographic measures of RV functions (TAPSE, Sa and RV FAC) decreased as the LV ejection fraction decreased signifying that RV function was significantly dependent on LV function. These findings were consistent to the findings of the study by J L Caplin et al,[7] PfistererM et al[8] and A Marmor et al.[9] In these studies also RV function was dependent on LV ejection fraction in patients with AWMI, but it is independent of LV EF in patients with IWMI.

These findings suggest the pathophysiological mechanisms of RV dysfunction in acute myocardial infarction. In AWMI the RV dysfunction is predominantly due to LV dysfunction which causes acute increase in afterload of RV leading to contractile dysfunction of RV. In contrast, in IWMI the RV dysfunction was probably due to direct involvement of $\mathrm{RV}$ myocardium due to ischaemia.

There was no significant difference in echocardiographic RV functional parameters between patients who were given thrombolytic therapy and those who were not given thrombolytic therapy. These findings were similar to the studies of Roth A et al[10] and Tabone $X$ et al[11] which suggested thrombolytic therapy was of little benefit in improving RV function early after MI. In another study by Kinn et al,[12] there was rapid improvement in haemodynamics only in patients with successful reperfusion of the infarct related artery after thrombolytic therapy. Probably failed reperfusion or early stunning of RV might have contributed to these findings in our study.

\section{CONCLUSION}

Nearly one fourth of patients with Acute ST-Elevation Myocardial Infarction had right ventricular dysfunction. LV dysfunction contributes significantly to RV dysfunction in acute myocardial infarction more so in anterior wall MI. As the severity of LV dysfunction increases RV function worsens.

\section{REFERENCES}

[1] Kaul S, Tei C, Hopkins JM, et al. Assessment of right ventricular function using two-dimensional echocardiography. Am Heart J 1984;107(3):526-31.

[2] Alam M, Wardell J, Andersson E, et al. Right ventricular function in patients with first inferior myocardial infarction: assessment by tricuspid annular motion and tricuspid annular velocity. Am Heart J 2000;139(4):710-5.

[3] Zornoff LA, Skali H, Pfeffer MA, et al. Right ventricular dysfunction and risk of heart failure and mortality after myocardial infarction. J Am Coll Cardiol 2002;39(9):1450-5. 
[4] Lang RM, Bierig $M$, Devereux RB, et al. Recommendations for chamber quantification: a report from the American society of echocardiography's guidelines and standards committee and the chamber quantification writing group, developed in conjunction with the European association of echocardiography, a branch of the European society of cardiology. J Am Soc Echocardiogr 2005;18(12):1440-63.

[5] Meluzin J, Spinarova L, Bakala J, et al. Pulsed Doppler tissue imaging of the velocity of tricuspid annular systolic motion: a new, rapid, and non-invasive method of evaluating right ventricular systolic function. Eur Heart J 2001;22(4):340-8.

[6] Tamborini G, Pepi M, Galli CA, et al. Feasibility and accuracy of a routine echocardiographic assessment of right ventricular function. International Journal of Cardiology 2007;115(1):86-9.

[7] Caplin JL, Dymond DS, Flatman WD, et al. Global and regional right ventricular function after acute myocardial infarction: dependence upon site of left ventricular infarction. Br Heart J 1987;58(2):101-9.
[8] Pfisterer $M$, Emmenegger $H$, Müller-Brand J, et al. Prevalence and extent of right ventricular dysfunction after myocardial infarction-relation to location and extent of infarction and left ventricular function. Int J Cardiol 1990;28(3):325-32.

[9] Marmor A, Geltman EM, Biello DR, et al. Functional response of the right ventricle to myocardial infarction: dependence on the site of left ventricular infarction. Circulation 1981;64(5):1005-11.

[10] Roth A, Miller HI, Kaluski E, et al. Early thrombolytic therapy does not enhance the recovery of the right ventricle in patients with acute inferior myocardial infarction and predominant right ventricular involvement. Cardiology 1990;77:40-9.

[11] Tabone $X$, Vacheron A. Should inferior myocardial infarction be thrombolysed? Arch Mal Coeur Vaiss 1992;85(4):449-52.

[12] Kinn JW, Ajluni SC, Samyn JG, et al. Rapid hemodynamic improvement after reperfusion during right ventricular infarction. J Am Coll Cardiol 1995;26(5):1230-4. 